\title{
Epidemiological Characteristics and Management of Brain Metastases on Patients in the Clinical Hospital of the University of Chile (Hcuch) between 2012 and 2017
}

\author{
Gustavo Zomosa ${ }^{1}$, Lucas González ${ }^{2}$, Martin Aguirre², Sebastián Castro² and Eduardo Villa² \\ ${ }^{1}$ Department of Neurology and Neurosurgery, University of Chile Clinical Hospital, Chile
}

${ }^{2}$ Faculty of Medicine, University of Chile, Chile

*Corresponding author: Gustavo Zomosa Rojas, Department of Neurology and Neurosurgery, University of Chile Clinical Hospital, Chile.

To Cite This Article: : Gustavo Zomosa Rojas. Epidemiological Characteristics and Management of Brain Metastases on Patients in the Clinical Hospital of the University of Chile (Hcuch) between 2012 and 2017. Am J Biomed Sci \& Res. 2019 - 2(5). AJBSR.MS.ID.000608.

DOI: 10.34297/AJBSR.2019.02.000608

Received: April 16, 2019 | Published: May 02, 2019

\begin{abstract}
Introduction and Context: Brain metastases (BM) are the main neurological complication of cancer, affecting up to $30 \%$ of these patients (incidence $=8.3-14.3 \times 100,000$ ), and they are the most frequent intracranial tumors (IT) of the adult. They are 10 times more common than primary cerebral neoplasms (PCN), however, the number of publications about this pathology is only $25 \%$ of PCNs such as gliomas. In our country there is no national registry of brain tumors, so the actual incidence of these is unknown. Treatments include initial/palliative management with glucocorticoids (GC) and/or surgery (Cx), radiosurgery (RS) or Whole Brain Radiation Therapy (WBRT). The purpose of this study is to determine clinical and therapeutic characteristics of BM in patients taken care of in our institution and with this information we propose the improvement of the management of these patients.
\end{abstract}

Material and Methods: In this cohort study we analyze the clinical records of patients treated in our hospital during the years 2012-2017 with a diagnosis of BM. The date of death was obtained from the National Identification Registry and Identification Service and calculated the median survival between diagnosis and death. We registered: sex, age at diagnosis, number of brain metastases, management and survival rate.

Results: 54 CR were found with a diagnosis of BM, however, only 31 complied with Inclusion criteria (IC). Average age at diagnosis of symptomatic BM: 59 years (range: 29-86 years), men $(n=13): 56.3$ years and in women $(n=18): 60.9$ years. BM number: 14 patients $(45,1 \%)$ had one BM; 11 (35,5\%) had oligometastases (2 or 3); and $6(19,4 \%)$ patients multiple BM (more than 3). Origin of primary tumor: $45.2 \%$ pulmonary; $12.9 \%$ colorectal; $12.9 \%$ renal; $9.7 \%$ breast; $3.2 \%$ ovary; $3.2 \%$ unknown; $12.9 \%$ other (Includes gastric, hepatic and thyroid). Only $38.7 \%$ of BM had BB, $25 \%$ were poorly differentiated lung carcinoma, $16.7 \%$ colon adenocarcinoma and $16.7 \%$ moderate/poorly differentiated breast carcinoma. Clinical Features (CF) highlights includes motor symptoms and signs in 54,8\%, headache in $48,4 \%$ and gait apraxia in 38,7\%. Location: 67.7\% of patients had hemispheric tumors and 35.5\% cerebellar. There were no brainstem tumors in our study. 12 (38.7\%) patient received active treatment (surgery or radiosurgery),11 (35.5\%) had surgery and only one (3.2\%) received radiosurgery. All patients received palliative care, and 10 received WBRT. Survival: one patient was alive. For those who had a certified death, average survival time after diagnosis was 34.9 weeks ( $N=30$ ). People who received active treatment, had an average survival time of 56.1 weeks after diagnosis and 54.5 weeks after treatment ( $\mathrm{N}=12)$. Patients which did not receive an active treatment $(\mathrm{N}=18)$ had an average survival of 20.7 weeks. The hazard rates differ between those who had an active treatment and those who did not (log-rank test), $\mathrm{z}$ test $=2.25, \mathrm{p}=0.0246)$. The survival -in weeks- of patients who WBRT $(\mathrm{N}=10)$ versus those that were only managed with palliative care $(\mathrm{GC})(\mathrm{N}=8)$ was $\mathrm{z}$ test $=2.76, \mathrm{p}=0.00578$. In the group of people who received active treatment, there was no difference between the ones that had unique BM vs those with 2 or $3 \mathrm{BM}$. In the group that received active treatment, $3(25 \%)$ patients died because of their BM but there was no difference with the palliative group.

Conclusion: BM is a prevalent oncological complication. The age of presentation is primarily between 4th-7th decade of life, the main primary tumor comes from lung, and the main location is at the frontal lobe. All patients should be given palliative treatment and active treatments are offered to selected patients with better prognosis. The average survival for patients with active treatment in our institution is 54.5 weeks better than the WBRT and palliative group. 
Keywords: Cancer; Brain metastases; Brain radiotherapy; Palliative care

Abbrevations: PCN: Primary Cerebral Neoplasms; BM: Brain Metastases; IT: Intracranial Tumors; CNS: Central Nervous System; CF: Clinical Features; GC: Glucocorticoids; SRS: Stereotactic Radiosurgery; WBRT: Whole Brain Radiation Therapy; CR: Clinical Records; IC: Inclusion Criteria; BB: Brain Biopsies; EC: Exclusion Criteria

\section{Introcdution}

Brain metastases $(\mathrm{BM})$ is the main direct neurological complication of cancer and the most frequent intracranial tumors (IT) in adults [1]. They are ten times more frequent than primary cerebral neoplasms (PCN) and its current management involves mostly palliative therapy but is at this moment evolving towards an active therapy either by surgical means or radiosurgery, which has shown a better prognosis [2]. The number of published papers on BM only achieves 25\% of gliomas [3]. Metastases to Central Nervous System (CNS) are common, affect $30 \%$ of patients with cancer [4]. BM are the most frequent expression of intracranial malignancy with an incidence varying between 8.3 and 14.3 per 100,000 [5]. However, are not the intracranial tumors most frequently operated, it is estimated that around $20-25 \%$ of BMs have a surgical indication. The candidates for surgery are patients with best prognostic factors, such as: age, controlled systemic disease, good functional status (Karnofsky), usually single and localized in non-eloquent area. The cause of death of these patients is in most cases due to metastatic disease and only $25 \%$ die of neurological causes [6]. In our country there is no national registry of brain tumors, so the actual incidence of these is unknown [7] $80 \%$ of CNS metastases are in the hemispheres, particularly in the territory of the middle cerebral artery and the posterior cerebral artery. In descending order: frontal, parietal, temporal and occipital [8]. The origin of BM highlights lung cancer, following with lower percentages breast cancer and melanoma [9]. BM are more frequent between the fifth and seventh decade of life and $75 \%$ of patients have multiple metastatic tumors [10]. The clinical features (CF) are varied, including headache as an initial symptom in $50 \%$ of patients [11]. Treatments include: initial/palliative management with glucocorticoids (GC) and/or surgery (Cx), stereotactic radiosurgery (SRS) or Whole Brain Radiation Therapy (WBRT) [6].

\section{Objective}

To study and describe epidemiological and clinical-therapeutic characteristics of BM patients in the Clinical Hospital of the University of Chile (HCUCH).

\section{Methodology}

This is a cohort study of a cross-section period between 2012 and 2017. The information was obtained from clinical records (CR) of patients treated at the HCUCH. Inclusion criteria (IC) and exclusion criteria (EC) were defined based on the available clinical records:

IC: adult patients diagnosed with BM during 2012-2017.

EC: incomplete registry and/or diagnostic doubt between primary brain neoplasm and BM.
The following data was registered: sex, age at diagnosis, BM number, clinical features, primary cancer, clinical status, management and outcome. We also reviewed reports of pathological anatomy of existing brain biopsies (BB) of patients who met the IC. The cause and date of death was obtained from the death certificates of the National Identification Registry and CR. Survival was estimated from the date of imagenologic diagnosis to the date of death for all patients. Subsequently, the information was analyzed, and the Kaplan-Meier survival curves were configured using the Log-Rank Test, comparing survival rates between active vs non-active treatment. Significance was established when $\mathrm{p}<0.05$. This report was approved by the ethics committee from HCUCH.

Results

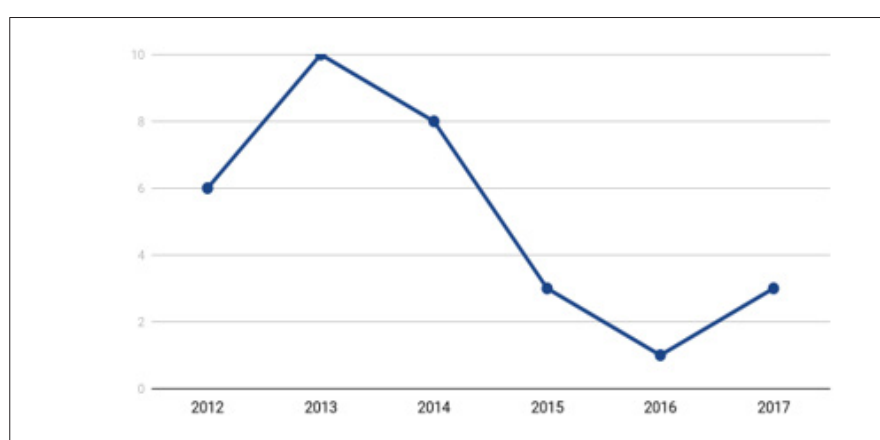

Graph 1: Case records of patients with cerebral metastases attended between 2012 and 2017 at $\mathrm{HCUCH}(\mathrm{N}=31)$.

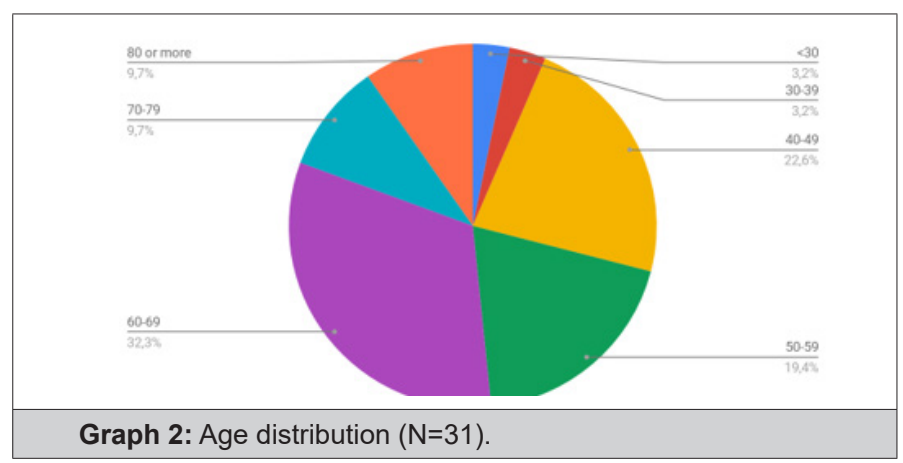

54 CR were found with a diagnosis of BM, however, only 31 complied with IC (Graph 1). Average age at diagnosis of symptomatic BM: 59 years (range: 29-86 years), men $(n=13): 56.3$ years and in women (n=18): 60.9 years (Graph 2). BM number (Graph 3): 14 patients $(45,1 \%)$ had one BM; $11(35,5 \%)$ had oligometastases $(2$ or 3); and $6(19,4 \%)$ patients multiple BM (more than 3). Origin of primary tumor: $45.2 \%$ pulmonary; $12.9 \%$ colorectal; $12.9 \%$ renal; 9.7\% breast; $3.2 \%$ ovary; $3.2 \%$ unknown; $12.9 \%$ other (Includes gastric, hepatic and thyroid) (Graph 4). Only 38.7\% of BM had BB, 25\% were poorly differentiated lung carcinoma, 16.7\% colon adenocarcinoma and $16.7 \%$ moderate/poorly differentiated breast 
carcinoma (Graph 5). Clinical Features (CF) highlights includes motor symptoms and signs in $54,8 \%$, headache in $48,4 \%$ and gait apraxia in $38,7 \%$ (Table 1). Location: $67.7 \%$ of patients had hemispheric tumors and $35.5 \%$ cerebellar (Figure 1). There were no brainstem tumors in our study. $12(38.7 \%)$ patients received active treatment (surgery or radiosurgery),11 (35.5\%) had surgery: tumor resection including one ventricular peritoneal shunt and only one $(3.2 \%)$ treated with radiosurgery. All patients received palliative care, and 10 received WBRT.

Graph 3: Number of BM per patient.
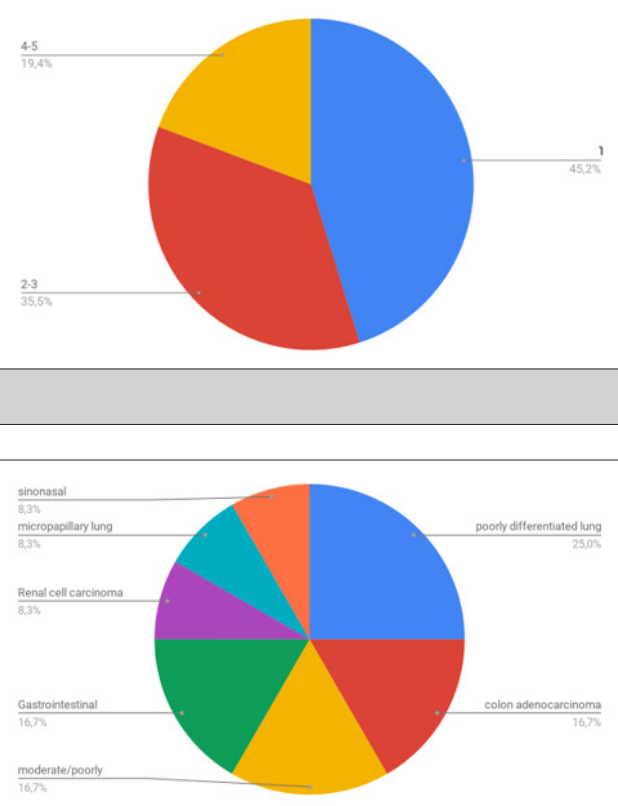

Graph 4: Histology of brain biopsies $(\mathrm{N}=12)$

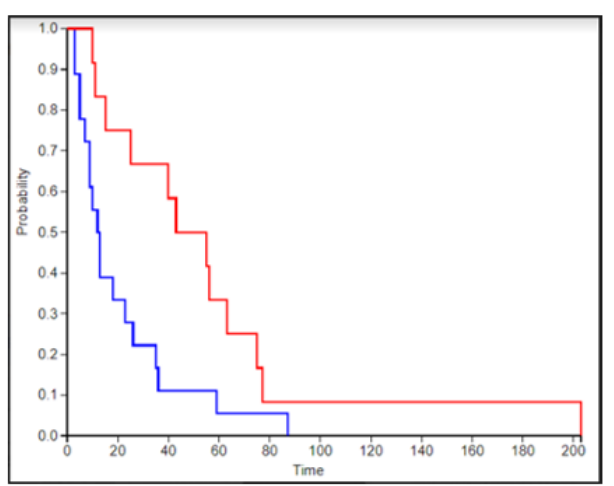

Graph 5: Survival curve between the group of death patients that were candidate to active management (red line $n=12$ ) versus those that were managed with palliative care (blue line $n=18)$. Time expressed in weeks $(N=30) . z=2.25, p=0.0246$.

Table 1: Frequency of symptoms and signs at clinical onset.

\begin{tabular}{|c|c|c|c|c|c|}
\hline Findings at the debut & Total $(\mathrm{N}=31)$ & Male $(\mathrm{N}=13)$ & Female $(\mathrm{N}=18)$ & $<50$ years $(\mathrm{N}=9)$ & $>50$ years $(\mathrm{N}=22)$ \\
\hline Headache & $48.38 \%$ & $38.46 \%$ & $55.56 \%$ & $66.67 \%$ & $40.91 \%$ \\
\hline Cognitive impairment & $25.80 \%$ & $23.08 \%$ & $27.77 \%$ & $0 \% *$ & $36.36 \%$ \\
\hline Aphasia & $19.35 \%$ & $15.38 \%$ & $22.22 \%$ & $11.11 \%$ & $22.73 \%$ \\
\hline Gait Apraxia & $38.71 \%$ & $38.46 \%$ & $38.89 \%$ & $0 \% * *$ & $54.55 \%$ \\
\hline Cerebellar signs & $35.48 \%$ & $23.08 \%$ & $44.44 \%$ & $11.11 \%$ & $45.45 \%$ \\
\hline Vomiting & $29.03 \%$ & $30.77 \%$ & $27.77 \%$ & $33.33 \%$ & $27.27 \%$ \\
\hline Motor symptoms* and signs (paresis and plegia) & $54.83 \%$ & $38.46 \%$ & $66.67 \%$ & $44.44 \%$ & $59.09 \%$ \\
\hline Sensory impairment & $25.80 \%$ & $30.77 \%$ & $22.22 \%$ & $33.33 \%$ & $22.73 \%$ \\
\hline Visual disturbance & $9.60 \%$ & $7.69 \%$ & $11.11 \%$ & $11.11 \%$ & $9.09 \%$ \\
\hline
\end{tabular}

Note: *Cognitive impairment was found only in the group $>50$ years. may be because of there were only three frontal BM with mild simptoms.

${ }^{* *}$ Gait apraxia may be by less posterior fosa oligometastases. 


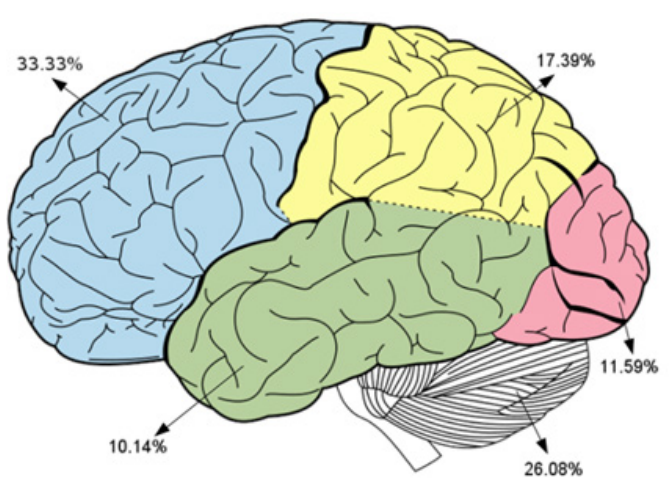

Figure 1: Distribution of $\mathrm{BM}$ by location ( $\mathrm{N}=69$ tumors).

Survival: One patient is still alive. For those who had a certified death, average survival time after diagnosis was 34.9 weeks $(\mathrm{N}=30)$. People who received active treatment, had an average survival time of 56.1 weeks after diagnosis and 54.5 weeks after treatment $(\mathrm{N}=12)$. Patients which did not receive an active treatment $(\mathrm{N}=18)$ had an average survival of 20.7 weeks. The hazard rates differ between those who had an active treatment and those who did not (log-rank test), $\mathrm{z}$ test $=2.25, \mathrm{p}=0.0246)$. The survival in weeks of patients who WBRT $(\mathrm{N}=10)$ versus those that were only managed with palliative care $(\mathrm{GC})(\mathrm{N}=8)$ was $\mathrm{z}$ test $=2.76, \mathrm{p}=0.00578$ (Graph 6). In the group of people who received active treatment, there was no difference between the ones that had unique BM vs those with 2 or 3 BM (Graph 7). Cause of death: In the group that received active treatment, $3(25 \%)$ patients died because of their BM but there was no difference with the palliative grow. Future Proposals: Improvements to this project could include a multicentric analysis and a more thorough.

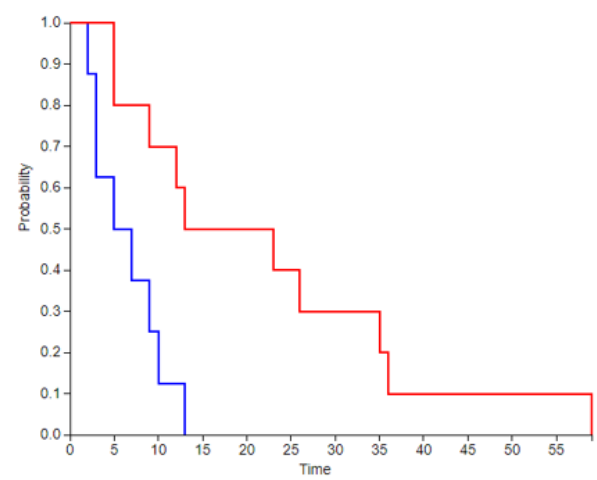

Graph 6: Survival curve between the group of death patients that were candidate to active management (red line $n=12$ ) versus those that were managed with palliative care (blue line $n=18$ ). Time expressed in weeks $(N=30) . z=2.25, p=0.0246$.

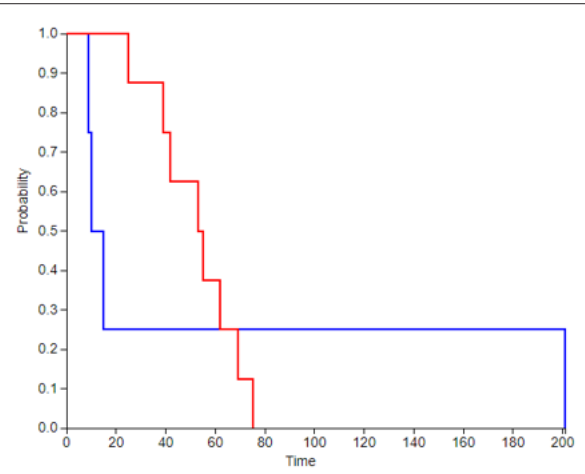

Graph 7: Survival curve between the group of death patients that were candidate to active management with unique metastases (red line $n=8$ ) versus those with active management and oligometastases (blue line $n=4)$. Time expressed in weeks $(N=12) . z=0.27, p=0.79$.

\section{Discussion}

There are few Chilean studies about BM $[2,12]$ In this study the age of presentation is mainly between 50 and 70 years (59.4\%), including an important group of patients who were reported in their 4 th decade of life $(22.6 \%)$. Also $45.1 \%$ of patients had a single BM, 35.5\% oligometastases and $19.4 \%$ of patients emerged with multiple BM, incidence that has not been reported as in other studies [10]. According to previous reports the leading origin of 
primary tumor was pulmonary (45.2\%), but our breast incidence (9.7\%) was lower than other reports and colorectal and renal (12.9\%) were higher. None of our patients was reported with melanoma. A major group displayed hemispheric tumors (frontal parietal, occipital, temporal) followed by a significant pool of cerebellar tumors, as in other papers [10]. The clinical presentation coincides with the literature including headache in nearly $50 \%$ of patients, and an important group with motor symptoms and signs (54.8\%) and gait apraxia (38.7\%). Cognitive impairment was found only in the group $>50$ years. may be because of there were only three frontal BM with mild symptoms and also gait ataxia was not found because of less posterior fossa oligometastases.

According with other studies [13] 25\% of our patients with active treatment died because of neurological associated causes. It is important to consider that only patients in good functional status and with a small number and size of BM were candidates to active treatment. There was an atmost significant difference in survival between patients who received active treatment and the group treated with palliative management $(\mathrm{p}<0.03)$. This result supports the active management in selected patients $[12,14]$. In our country radiosurgery is not available for all patients that is the reason for only one patient treated. There was also a significant difference when we compared WBRT versus palliative management. This has been reported in the literature since several years [15].

\section{Conclusion}

Brain Metastases are an important oncologic complication. As in other studies, we found that the average age of presentation is in between the fourth and seventh decade of life, also that pulmonary cancer is the main primary on these patients and the main location for these metastases is the frontal lobe. Palliative care is mandatory for all these patients, but active management must be given to selected patients with a better prognosis. All patients should be discussed in the neuro-oncological committee to evaluate the possibility for an active treatment such as surgical or radio surgical treatment. Future Proposals: Improvements to this project could include a multicentric analysis.

\section{References}

1. Saha A, Ghosh SK, Roy C, Choudhury KB, Chakrabarty B et al. (2013) Demographic and clinical profile of patients with brain metastases: A retrospective study. Asian J Neurosurg 8(3): 157-161.

2. Lovo I Eduardo, Torrealba M Gonzalo, Villanueva G Pablo, Gejman Roger, Tagle M Patricio (2005) Metástasis cerebral y sobrevida. Rev méd Chile 133(2): 190-194.

3. Preusser M, Weller M (2015) Brain metastasis research: a late awakening. Chin Clin Oncol 4(2): 4-5.

4. Barani IJ, Larson DA, Berger MS (2013) Future directions in treatment of brain metastases. Surg Neurol Int 4(Suppl 4): S220-S230.

5. Nayak L, Lee EQ, Wen PY (2012) Epidemiology of brain metastases. Curr Oncol Rep 14(1): 48-54.

6. Zomosa G, González L, Miranda G, Galleguillos MF (2018) Metástasis encefálicas, actualización de manejo. Rev Hosp Clin Univ Chile.

7. Contreras LE (2017) Epidemiología De Tumores Cerebrales. Rev Médica Clínica Las Condes 28(3): 332-338.

8. Delattre JY, Krol G, Thaler HT, Posner JB (1988) Distribution of brain metastases. Arch Neurol 45(7): 741-744.

9. Ellison D, Love S, Chimelli LM, Harding B, Lowe J et al. (2012) Neoplasms that spread to the CNS. Neuropathology ( $3^{\text {rd }} e d n$ ), pp. 849-856.

10. Barnholtz Sloan JS, Sloan AE, Davis FG, Vigneau FD, Lai P et al. (2004) Incidence proportions of brain metastases in patients diagnosed (1973 to 2001) in the Metropolitan Detroit Cancer Surveillance System. J Clin Oncol 22(14): 2865-2872.

11. Forsyth PA, Posner JB (1993) Headaches in patients with brain tumors: a study of 111 patients. Neurology 43(9): 1678-1683.

12. Poblete T, Donoso MT, Holzer F (2008) Caracterizacin de pacientes operados de metástasis cerebral en el Instituto de Neurocirugía Asenjo (INCA). Rev Chil Neuro-Psiquiat 46(2): 101-106.

13. Luján M (2005) Enfoque diagnóstico y manejo básico de las metástasis cerebrales Diagnostic evaluation and basic management of brain metastases. Rev Colomb Can Ce Rol 10:61.

14.Zomosa G, Gonzalez L, Miranda G, Galleguillos MF (2018) Brain Metastases, Update in management. Tech Neurosurg Neurol 2(2): 1-9.

15. Patel AJ, Lang FF, Suki D, Wildrick DM, Sawaya R (2017) Metastatic brain tumors. Youmans and Winn Neurological Surgery. ( $7^{\text {th }}$ edn), Elsevier, Philadelphia. PA, USA. 